\title{
Antecedents and Consequences of Trust in Public Sector Websites and Social Media
}

\section{Hüseyin İnce}

Gebze Technical University, Turkey | $\underline{\text { h.ince@gtu.edu.tr }}$

\section{Salih Zeki İmamoğlu}

Gebze Technical University, Turkey | $\underline{\text { imamoglu@gtu.edu.tr }}$

\section{Hülya Türkcan}

Gebze Technical University, Turkey | hturkcan@gtu.edu.tr

\section{Gülsüm Akca}

Gebze Technical University, Turkey | gulsum.akca37@gmail.com

Volume 10 No 1 (2020) ｜ＩSSN 2158-8708 (online) ｜ DOI 10.5195/emaj.2020.182 | http://emaj.pitt.edu

\begin{abstract}
Rapidly developing information and communication technologies have an influence on the whole world and have become an ordinary part of everyday life. Not only people, but businesses and governments are affected by these changes. In this respect, governments use several online media platforms as their own digital face and thus keep pace with the developing technology. Considering the lacks in previous researches, the aim of this paper is to investigate the critical factors influencing the citizens' trust in public sector websites and social media and also the relationship among trust in the public sector, citizen satisfaction and trust in public sector websites and social media. By studying 607 citizens who are users of the website or social media service belonging to the municipalities in Turkey, we found that: (i) perceived quality, perceived usefulness, and facilitation conditions are the factors that affect the citizens' trust in public sector websites and social media, (ii) trust in the public sector websites and social media affects trust in the public sector and, (iii) trust in the public sector affects citizen satisfaction.
\end{abstract}

Keywords: Public Sector Social Media, Public Sector Website, Trusting Factors, Trust; Citizen Satisfaction

\section{(cc) BY}

New articles in this journal are licensed under a Creative Commons Attribution 3.0 United States License.

\section{ULIS D-Sente}

This journal is published by the University Library System of the University of Pittsburgh as part of its $\underline{\mathrm{D} \text {-Scribe Digital Publishing Program, and is cosponsored by the University of Pittsburgh Press. }}$. 


\section{Antecedents and Consequences of Trust in Public Sector Websites and Social Media}

\author{
Hüseyin İnce \\ Salih Zeki İmamoğlu \\ Hülya Türkcan \\ Gülsüm Akca
}

\section{Introduction}

Until the 2000s, by using the Internet, it was only possible to read the posts on the websites, watch videos and listen to the sound recordings, while with the emergence of Web 2.0 and coming into our daily lives, the Internet has become interactive and created an online world (Obar \& Wildman, 2015). People have adapted to these changes easily and quickly. Because it provides that world at users' fingertips. The development and spread of information as well as communication technologies (ICTs) have also a significant impact on the development of nations (Kassen, 2014). Therefore, public administrations and governments have adopted and used ICTs such as social media increasingly (Criado, SandovalAlmazan \& Gil-Garcia, 2013). Web 2.0 tools are used by the government both for external affairs, which are public relations and the announcement of the news and for internal affairs, which are intelligence services and public consultation (Osimo, 2008).

At the present time, both local and national governments around the world exist on the World Wide Web (WWW). The reason is that, taking place in the online world is not just an option today for governments. It is a requirement because of the necessity to provide both information and services effectively. Governments use official websites, e-government websites, and social media tools for this purpose. Both websites and social media give information, but in different ways. Social media give information shorter, for example, sharing updates, whereas websites present detailed information (Porumbescu, 2016)

All of the online channels used by governments and public sector aforementioned, provide many advantages to not only governments, but also to citizens. There is an increasing amount of research on the issue that government and also public sector use websites and social media tools, because this usage enables both sides which are government and citizens, to be advantageous. In few studies citizen trust model for online channels examined, but there is no empirical research handling this issue in more detail, well addressed and comprehensively. Hence, literature about citizen trust model for online channels is poor to determine critical factors influencing the citizens' trust in public sector websites and social media. Additionally, while there are studies evaluating citizens' trust in the government according to the use of and attitude toward the government's social media and websites (Parent, Vandebeek \& Gemino, 2005; Tolbert \&
Mossberger, 2006), the relationship between trust in government and trust in government's online services as well as websites has been largely neglected. Moreover, in the literature, trust in the government is not clear in relation to citizen satisfaction, since there are studies showing that both affect each other (Yoon, 2002; Welch, Hinnant \& Moon, 2004). This paper intends to contribute the literature by providing comprehensive research aiming to fill in the gap of related literature addressed. In this respect, it is aimed to present comprehensive and overall research, since there is a need to determine the factors affecting trust in public sector websites and social media and explain the relationships among trust in the public sector, citizen satisfaction and trust in public sector websites and social media.

The paper is structured as follows. First literature review, theoretical background and hypothesis development are presented. Next, research methodology and analysis results are reported. In the end, conclusion and discussion are summarized.

\section{Literature Review, Theoretical Background and Hypothesis Development}

The Public Sector's Use of Social Media and Websites

In the 1980s, when personal computer usage became widespread, every public administrator met information technology and IT usage of governments were initiated (Yıldız, 2007). In 2000, President Clinton presented to the public the first Web address and a number of new e-government initiatives, one of which was firstgov.gov offered by the federal state that is a government portal provided citizens with access to government information and services (Moon, 2002). Since then, the importance and necessity of online media for the government have been increasing and becoming widespread rapidly. Although it has a short history as mentioned, it has shown significant improvement and in recent years, the government uses online media effectively. These media enable the government to make information known publicly and facilitate citizen investigations, whereas they allow the government to receive feedback from the public (Hong, 2013). The aim of the government to use online media as a communication channel is to promote democratic values and ensure public trust in government (Hong, 2013).

Social media which uses Web 2.0 technology is inevitably everywhere now (Baccarella, Wagner, Kietzmann \& McCarthy, 2018) and also it creates an area for knowledge sharing and expression of thoughts (Dong, Liang \& He, 2017). Social media is defined as an internetbased application that enables to create and exchange content which is user-generated (Kaplan \& Haenlein, 2010). Its tools include social networking sites such as Facebook and Instagram, as well as applications that enable the information exchange such as blogs and wikis (Bhimani, Mention \& Barlatier, 2018). By using mobile and web technologies, social media provides interactive platforms that enable both individuals and communities to share, reconstruct, hash out and make a modification to 
contents (Kietzmann, Hermkens, McCarthy \& Silvestre 2011). The importance of social media for governments has attracted a great deal of attention and this has become a topic that has been addressed by various researchers (Criado et al., 2013). Because developments in ICTs are seen as a technological revolution and this affects the economy, culture and even politics to a great extent (Kassen, 2014). In recent years, public enterprises have adopted various social media tools such as social networking, blogs, and crowdsourcing and usage of them have modified the landscape of public administrations (Criado et al., 2013). Now municipalities also pay attention to online communication and use various social media channels in order to communicate with citizens (Guillamón, Ríos, Gesuele \& Metallo, 2016). This is because online media such as public sector websites provides communication and interaction between citizen and government, since it offers a communication space (Hong, 2013). As a result of this, public enterprises which use and promote Web 2.0 as well as social media tools are more conscious, innovative and even citizen-centric generally (Bonsón, Torres, Royo \& Flores, 2012).

\section{The Factors Influencing Citizens' Trust in Public Sector Websites and Social Media}

To examine the determining factors affecting citizens' trust in public sector websites and social media, a framework was developed based on the relevant literature. In this context, it was seen that several basic theories explaining the adoption and acceptance of technology and information systems have come to the fore. Hence, in this study, a holistic approach was adopted from a comprehensive perspective and the effects of factors based on the models which are technology acceptance theory (TAM), theory of reasoned action (TRA), and theory of acceptance and use of technology (UTAUT) on citizens' trust in public sector websites and social media were investigated. TAM explains that intention to use is affected by attitudes, and also perceived usefulness and perceived ease of use are the determinants of attitude (Davis, Bagozzi \& Warshaw, 1989). TRA is a basic model, which predicts intention to use. Based on the model, attitude toward behavior and subjective norm are affecting it (Fishbein \& Ajzen, 1975). UTAUT explains that performance expectancy, effort expectancy, social influence, and facilitating conditions are the determinants (Venkatesh, Morris, Davis \& Davis, 2003). Based on these theories, propensity to trust, perceived quality, perceived usefulness, facilitating conditions, privacy factors and perceived risk are examined as determinants of citizens' trust in public sector websites and social media with the intent of better understanding of its key determinants.

\section{The propensity to Trust}

The propensity to trust can be defined as eagerness to trust (Cheung \& To, 2017) and considered as a personal property (Mayer, Davis \& Schoorman, 1995). It is an important premise of trust (Mayer et al., 1995; Bélanger \& Carter, 2008; Colesca, 2009). Generally, it is of great importance in the early days of the relationships
(McKnight, Kacmar \& Choudhury, 2004). The effect of propensity to trust on trust to applications and web tools, which is being used rapidly by masses, is crucial especially due to the fact that although its useful aspects are known, there are also aspects which are black box yet (Bélanger \& Carter, 2008). The reason is that, it stimulates positive perceptions and makes it easy to trust (McKnight et al., 2004). Hence, we hypothesized that:

H1. The propensity to trust is positively related to trust in the public sector websites and social media.

\section{Perceived Quality}

Quality attributes in websites are 3 types: Information, system and service quality (Teo, Srivastava \& Jiang, 2008). Information quality is about the information offering by online services (Sá, Rocha \& Cota, 2016). System quality is about ease of handling and the reliability in technics of websites (Teo et al., 2008). Services quality is about the properties, which affect the online services directly (Sá et al., 2016). In this respect, the degree of meeting expectations of citizens determines the level of their perceived quality and it affects the citizen's attitude toward the public sector websites and social media and also e-government services (Aladwani, 2014). If the citizens encounter a high-quality website, social media, and e-government service, they think that it is adequate and useful, want to use it again and their confidence in them increases (Colesca, 2009). Hence, we hypothesized that:

$\mathrm{H} 2$. Perceived quality is positively related to trust in the public sector websites and social media.

\section{Perceived Usefulness}

Perceived usefulness is the level of conceiving that e-government enhances their own value for citizens (Liu \& Zhou, 2010). Therefore, it facilities internet adoption generally (Warkentin, Gefen, Pavlou \& Rose, 2002). Because citizens attach great importance to their own benefit, when online services provide benefits to the citizens and present useful information, the citizens increase the frequency of usage and trusts. Also, more citizens tend to use it (Chatzoglou, Chatzoudes \& Symeonidis, 2015). Briefly stated, perceived usefulness of website and social media services are decisive in terms of trust in the public sector websites and social media. Therefore, perceived usefulness enables to take an attitude toward them positively (Hung, Chang \& Yu, 2006; Horst, Kuttschreuter \& Gutteling, 2007). It also provides citizen's satisfaction (Liu \& Zhou, 2010), increases intention to use (Chatzoglou et al., 2015) and is seen as a fundamental determinant of trust (Horst et al., 2007; Colesca, 2009; Chatzoglou et al., 2015). Hence, we hypothesized that:

H3. Perceived usefulness is positively related to trust in the public sector websites and social media. 


\section{Facilitating Conditions}

Facilitating conditions is defined as a degree of belief that there is a sufficient infrastructure to enable the use of a system (Gupta, Singh \& Bhaskar, 2016). It is also related to the perception about whether the technology following own lifestyle or not, especially for the web services (AlAwadhi \& Morris, 2008). If users can get fast support in solving various system and technical problems, their usage and trust will increase. These conditions remove the obstacles in the system, make it easy to use and increase the usage (Venkatesh et al., 2003). Furthermore, if users can get fast support in solving various system and technical problems, their usage and trust will increase. The reason is that, they can conceive it also as a foul-weather friend. This is an important point to make. From this point of view, facilitating conditions improve adaption and usage of the website as well as social media (AlAwadhi \& Morris, 2008). Additionally, because facilitating conditions offer better experiences on the system and reduce the risks, it develops trust (Ratnasingam, 2004). As a consequence, it can deduce that facilitating conditions are the motivators of trust in online media. Hence, we hypothesized that:

H4. Facilitating conditions is positively related to trust in the public sector websites and social media.

\section{Privacy Factors}

Privacy is about that person being able to control and know how their personal information is shared with whom and what (Al-Jamal \& Abu-Shanab, 2015). In this respect, privacy is a concern for all people. With the Internet taking its place in everyday life, people began to have a particular concern about online privacy when they realized that their personal information could be collected outside their control (Dhillon, Oliveira \& Syed, 2018). Therefore, the security and privacy provided by that website or an online application play an important role for people to use and trust a website (Ayyash, Ahmad \& Singh, 2013). The reason is that, it is important whether people's expectations about privacy are met or not (Martin, 2018). The security of personal data and privacy of citizens are also ethical issues for the government (Gajendra, Xi \& Wang, 2012). The government must ensure usage and trust (Colesca, 2009; Abu-Shanab, 2014; Al-Jamal \& Abu-Shanab, 2015). Hence, we hypothesized that:

H5. Privacy factors are positively related to trust in the public sector websites and social media.

\section{Perceived Risk}

Perceived risk is related to uncertainty resulting from potential adverse outcomes (Featherman \& Pavlou, 2003). The online environment contains within itself a huge uncertainty. Namely, it is normal for online environments to have a high risk (Ranaweera, 2016). The following are the risks users may face when using an eservice or e-application: Performance, financial, time, psychological, social, privacy and overall risks (Featherman \& Pavlou, 2003). With respect to these risks, it is quite obvious that risk is closely associated with trust (Liu \& Zhou, 2010). People stay away from what they think is highly risky. Since people are not prone to risktaking, the desire to use online services such as social media decreases as long as the perceived risk increases (Warkentin et al., 2002). Hence, we hypothesized that:

H6. Perceived risk is negatively related to trust in the public sector websites and social media.

Trust in Public Sector Websites and Social Media and Trust in the Public Sector

Thanks to online media, increased transparency and efficiency that can increase trust by positively affecting the government's image (Tolbert \& Mossberger, 2006). Factors leading to trust are: Ability (skills and competencies in a specific area), benevolence (believing that the trustee is not selfish and take into account the interests of others), and integrity (a perception that trustee sticks to generally accepted principles) (Mayer et al., 1995). When considered from this point of view, citizens can trust in government and public sector, if it is equipped with abilities in the expected areas, act according to the interests of citizens and have integrity and honesty. Citizens trust in the online services of the public sector when they perceive it as beneficial, quality, confidential and nonhazardous (Colesca, 2009). They meet the three factors mentioned above. In terms of psychological distance, especially the government's use of social media increases citizens' positive feelings and thoughts about the government (Porumbescu, 2016). Additionally, considering that the government websites, social media accounts, and e-government are the digital faces of the government, it can be said that trust in them enhance trust in the government. The reason is that, getting easy access to the government by means of the online access provided by the e-government, websites and social media can be seen as a reason for trust in the government (Tolbert \& Mossberger, 2006). This also hinders the information asymmetry between government and citizens, thus it is possible to avoid prejudiced attitudes and ideas and promote trust in the government and public sector (Welch et al., 2004). Hence, we hypothesized that:

H7. Trust in the public sector websites and social media is positively related to trust in the public sector.

\section{Trust in the Public Sector and Citizen Satisfaction}

Satisfaction can be considered as an antecedent of trust. As a result of this, satisfaction and trust are interrelated constructs (Yoon, 2002; Welch et al., 2004; Teo et al., 2008). For instance, a person deciding whether to get a service or not depends on his/her own trust. At this stage, the trust may stem from his/her personal characteristics, perceived benefits, the degree of potential risks and convenience. After getting a service, the person 
compares the process and outcomes of using this service with own expectations. If the service meets his/her expectations, this person is satisfied. After the experience of getting service, the more he/she is satisfied, the more he/she trusts. In this context, it can be said that satisfaction is the antecedent of trust if this experience isn't the first. When considered in terms of getting a service or buying a product, it can be assumed that this cycle may continue. But here the relationship between trust in the public sector and citizen satisfaction is discussed. At this point, because the risks and cost may be higher, the citizen may refuse to associate with the public sector as far as possible if the citizen does not trust in the public sector. Therefore, satisfaction in citizens may not occur at all. Also, $\mathrm{Xu}$, Cenfetelli, and Aquino (2016) stated that benevolence and integrity, which are components of trust, increase satisfaction. Hence, we hypothesized that:

H8. Trust in the public sector is positively related to citizen satisfaction.

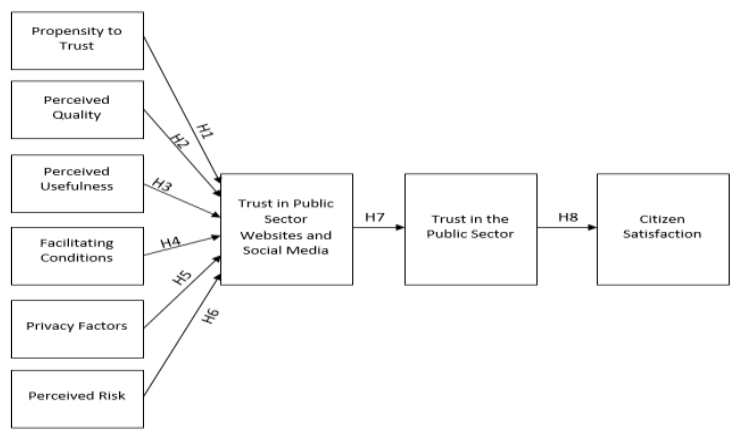

Figure 1. Proposed Research Model

\section{Research Method and Analysis}

\section{Measures and Sampling}

To test the hypotheses, multi-item scales were adapted from previous studies and we used a 5-point Likert scale. We adapted Bélanger and Carter (2008)'s items to assess propensity to trust and perceived risk. Perceived quality, trust in the public sector social media and trust in the public sector websites scales were adapted from Teo et al. (2008). The scales for perceived usefulness and facilitating conditions were adapted from Venkatesh et al. (2003). For privacy factors, the scale was adapted from $\mathrm{Ho}$ and $\mathrm{Li}$ (2011). Finally, the scales to assess trust in the public sector and citizen satisfaction were adapted from Porumbescu (2016).

The survey method was used for collecting data. To be sure that all the items which constitute the questionnaire are translated truthfully, the parallel translation was done. Therefore, all the items were translated into Turkish and then translated into English again. Thus, the accuracy of translation could prove out. After making sure of it, a pilot study was undertaken by getting across 40 respondents and their comments were received in order to have a clear and understandable final version of the questionnaire. Then, 750 surveys were distributed and 607 of them returned $(80.9 \%$ response rate). The respondents are people using website and/or social media services of municipalities in Turkey. Besides, concerning our sample, $65 \%$ are female, $50 \%$ are between $31-45$ years old and $55 \%$ have a university degree.

\section{Measure Validity and Reliability}

First of all, exploratory factor analysis is applied to test the construct validity of measures. For the exploratory factor analysis, principal components extraction with varimax rotation is performed. Besides, the Kaiser-Meyer-Olkin (KMO) measure which shows the sample adequacy and Bartlett's test of Sphericity are used. The KMO index is .969 , and Bartlett's test of sphericity yields a statistically significant level of 0.00 . $(\mathrm{x} 2=24938.115, \mathrm{p}=.00)$. These results justified the carrying out of exploratory factor analysis.

The results of the exploratory factor analysis are shown in Table 1. Of 59 items, 17 items which are loaded into more than one factor, loaded on one factor alone or not being charged to any factor are eliminated. 42 items remained and these were loaded into 8 factors. Privacy factors and perceived risk are excluded, because no factors were loaded on them. It is also seen that although the perceived quality variable is composed of three dimensions as information, service and system quality, it is observed that the information and service quality are loaded on the same factor and system quality is loaded on a factor. As a result, it is structured in 2 dimensions. In addition, trust in the municipality's website and trust in the municipality's social media which are considered as separate factors are loaded on the same factor. Obtained 8 factors explain $77.10 \%$ of the variance.

Table 1: The Results of the Exploratory Factor Analysis

\begin{tabular}{|c|c|c|c|c|c|c|c|c|c|}
\hline Factora & Items & 1 & 2 & 3 & 4 & 5 & 6 & 7 & 8 \\
\hline Trust in & Trustinps_12 & .91 & & & & & & & \\
\hline Public & Trustinps_11 & .90 & & & & & & & \\
\hline \multirow[t]{9}{*}{ Sector } & Trustinps_6 6 & .90 & & & & & & & \\
\hline & Trustinps_7 & .89 & & & & & & & \\
\hline & Trustinps_9 9 & .89 & & & & & & & \\
\hline & Trustinps_8 8 & .89 & & & & & & & \\
\hline & Trustinps_10 & .86 & & & & & & & \\
\hline & Trustinps_4 & .86 & & & & & & & \\
\hline & Trustinps_5 5 & .84 & & & & & & & \\
\hline & Trustinps_2 & .82 & & & & & & & \\
\hline & Trustinps_ 3 & .76 & & & & & & & \\
\hline Citizen & Satisfaction_1 & & .98 & & & & & & \\
\hline Satisfaction & Satisfaction_2 & & .92 & & & & & & \\
\hline \multirow{9}{*}{$\begin{array}{l}\text { Perceived } \\
\text { Information } \\
\text { and Service } \\
\text { Quality }\end{array}$} & Pquality_2 & & & .93 & & & & & \\
\hline & Pquality_1 & & & .92 & & & & & \\
\hline & Pquality_4 & & & .86 & & & & & \\
\hline & Pquality_17 & & & .77 & & & & & \\
\hline & Pquality_7 & & & .71 & & & & & \\
\hline & Pquality_19 & & & .70 & & & & & \\
\hline & Pquality_5 & & & .66 & & & & & \\
\hline & Pquality_11 & & & .66 & & & & & \\
\hline & Pquality_18 & & & .65 & & & & & \\
\hline Trust in & Trustinwws_3 & & & & .91 & & & & \\
\hline Public & Trustinsm_l & & & & .90 & & & & \\
\hline Sector & Trustinsm_3 & & & & 84 & & & & \\
\hline \multirow{5}{*}{$\begin{array}{l}\text { Websites } \\
\text { and Social } \\
\text { Media }\end{array}$} & Trustinsm_2 & & & & .76 & & & & \\
\hline & Trustinws_1 1 & & & & .75 & & & & \\
\hline & Trustinws_2 2 & & & & .75 & & & & \\
\hline & Pusefulness_2 & & & & & .93 & & & \\
\hline & Pusefulness_4 & & & & & .83 & & & \\
\hline
\end{tabular}




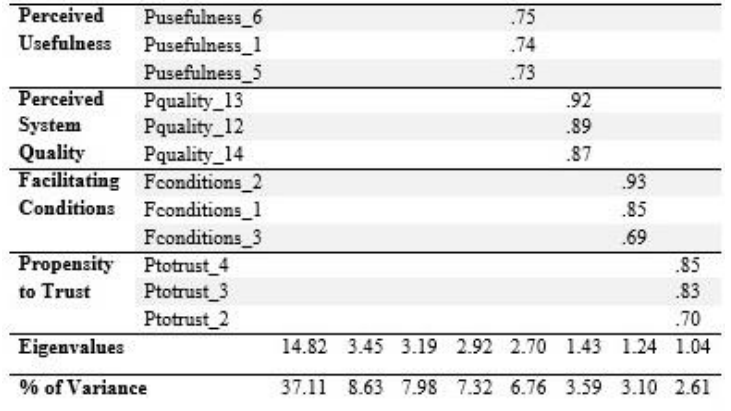

Table 2 presents the calculated means and standard deviations, Cronbach's alphas for obtained factors and also correlation coefficients. The values of Cronbach's alpha which is used to assess reliability, are ranging from .72 to .98 . Since 0,7 is a threshold that determines whether the scales are reliable according to Nunnally (1978), it is considered that all the measurement scales are internally reliable.

Table 2: Factor Correlations, Cronbach's Alphas, Means and Standard Deviations

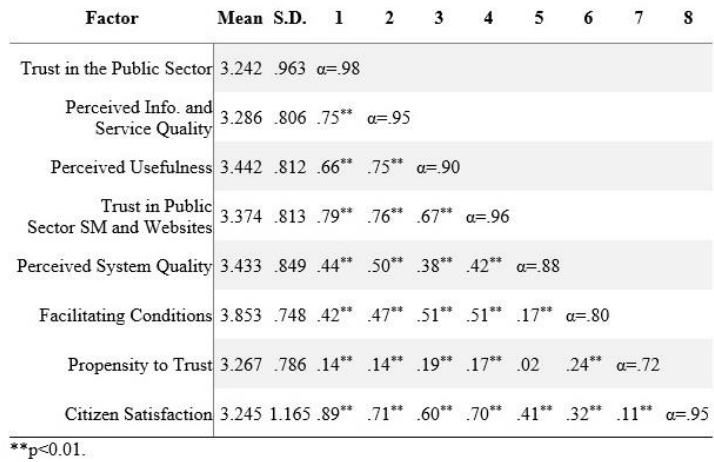

\section{Hypothesis Testing}

To test our hypotheses, we handled regression analyses. Table 3 reveals the results of regression analyses. Regression analysis results indicate that perceived information and service quality $(\beta=.54, p<.01)$, perceived system quality $(\beta=.06, \mathrm{p}<.05)$, perceived usefulness $(\beta=.15, p<.01)$ and facilitating conditions $(\beta$ $=.17, \mathrm{p}<.01)$ are positively associated with trust in the public sector websites and social media. However, there is no relationship between propensity to trust and trust in the public sector websites and social media $(\beta=.03, \mathrm{p}>.05)$. Therefore, $\mathrm{H} 2, \mathrm{H} 3$, and $\mathrm{H} 4$ are supported whereas $\mathrm{H} 1$ is not supported. As seen in Table 3, trust in the public sector social media and websites is associated with trust in the public sector $(\beta=.93, p<.01)$, supporting H7. Finally, when the association between trust in the public sector and citizen satisfaction is investigated, it is seen that they are related significantly $(\beta=1.08, \mathrm{p}<.01)$. Hence, $\mathrm{H} 8$ is supported.
Table 3: The Results of the Regression Analyses

\begin{tabular}{|c|c|c|c|c|c|c|c|}
\hline Independent Variables & $\begin{array}{c}\text { Dependent } \\
\text { Variable }\end{array}$ & $\beta$ & t & Sig. & $\mathrm{R}^{2}$ & F & Sig. \\
\hline Propensity To Trust & \multirow{5}{*}{$\begin{array}{l}\text { Trust in Public } \\
\text { Sector Websites } \\
\text { and Social } \\
\text { Media }\end{array}$} & .03 & 1.29 & .20 & \multirow{5}{*}{.62} & \multirow{5}{*}{197.39} & \multirow{5}{*}{.00} \\
\hline $\begin{array}{l}\text { Perceived Info. And Service } \\
\text { Quality }\end{array}$ & & $.54 * *$ & 12.85 & .00 & & & \\
\hline Perceived System Quality & & $.06 *$ & 2.30 & .02 & & & \\
\hline Perceived Usefulness & & $.15^{* *}$ & 3.82 & .00 & & & \\
\hline Facilitating Conditions & & $.17 * *$ & 5.20 & .00 & & & \\
\hline $\begin{array}{l}\text { Trust in Public Sector } \\
\text { Websites and SM }\end{array}$ & $\begin{array}{l}\text { Trust in Public } \\
\text { Sector }\end{array}$ & $.93 * *$ & 31.29 & .00 & .62 & 979.16 & .00 \\
\hline Trust in Public Sector & $\begin{array}{l}\text { Citizen } \\
\text { Satisfaction }\end{array}$ & $1.08^{* *}$ & 48.58 & .00 & .80 & 2359.99 &, 00 \\
\hline
\end{tabular}

\section{Discussion and Conclusion}

This paper contributes to the literature by clarifying the relationship among trust in the public sector, citizen satisfaction, trust in public sector websites and social media. Also, the research reveals critical factors influencing the citizens' trust in public sector websites and social media. The findings show that perceived quality, perceived usefulness and facilitating conditions are the factors influencing the trust in the public sector websites and social media. Previous research shows that perceived quality (e.g. Colesca, 2009; Alsaghier, Ford, Nguyen \& Hexel, 2011), perceived usefulness (e.g. Colesca, 2009; Chatzoglou et al., 2015) and facilitating conditions (e.g. AlAwadhi \& Morris, 2008) affect the citizen usage of government online services such as websites, social media accounts and e-government services as well as trust in them. In this context, our results empirically promoted the previous research. It is also found that, there is no relationship between propensity trust and trust in the public sector websites as well as social media. McKnight, Cummings, and Chervany (1998) indicate that propensity trust affects the initial trust of people. Therefore, this finding stems from the fact that our participants are familiar with public sector websites and social media. It implies that, the expectations of citizens about online services should be learned and websites and social media accounts should be structured as regards the information about these expectations in order to meet them by public institutions. Furthermore, they should be easy for citizens to use, benefit them and facilitate their relations with the public sector.

Second, this study reveals the effect of trust in the public sector websites and social media on trust in the public sector. Tolbert, and Mossberger (2006) and Welch et al. (2004) found that trust in e-government affects trust in government. Also, Park, Choi, Kim, and Rho (2015) shows that trust in the government's social media services affects trust in government. Namely, our result is consistent with the previous studies. It can be stated that, online services are an issue that the public sector needs to consider important. Because, online services are the easiest meeting point for citizens and public institutions in today's information age. Transparent and up-to-date 
interaction with citizens through the website and social media can significantly increase trust in the public sector.

Third, this research demonstrated the effect of trust in the public sector on citizen satisfaction. Some studies handled these construct as interrelated (Yoon, 2002; Welch et al., 2004) before. Van Ryzin (2007) found that, the outcome of overall citizen satisfaction influences trust in government. Our finding shows that trust in government affects citizen satisfaction. This brought a new perspective to the relevant literature. According to our findings, public institutions should have competence, benevolence, and honesty since they win the trust of citizen (Xu et al., 2016). Thus, it will be possible to ensure citizen satisfaction.

Like all empirical researches, this study is subject to some limitations. First, this research was conducted with users of the website or social media service belonging to the municipalities in Turkey. So generalizability of our results is a limitation. However, further studies can enlarge or differentiate the sample through shedding light on this research. Secondly, this study is prone to common method bias.

This study is expected to be forefoot for new studies that will contribute to the development of relevant literature. Researchers can examine the citizen's habit of usage for online services in general and its effects can be analysed as well. This model can also be tested by conducting with users of other public institutions.

\section{References}

Abu-Shanab, E. (2014). Antecedents of trust in egovernment services: an empirical test in Jordan. Transforming Government: People, Process and Policy, 8(4), 480-499.

Aladwani, A. M. (2014). Cognitive beliefs about and the positive psychological tendency towards eGovernment quality. Procedia-Social and Behavioral Sciences, 127, 570-574.

AlAwadhi, S., \& Morris, A. (2008). The Use of the UTAUT Model in the Adoption of Egovernment Services in Kuwait. Proceedings of the 41st Annual Hawaii International Conference on System Sciences, 1-11.

Al-Jamal, M., \& Abu-Shanab, E. (2015). Privacy Policy of E-Government Websites and the Effect on Users' Privacy. The 7th International Conference on Information Technology, 338344.

Alsaghier, H., Ford, M., Nguyen, A., \& Hexel, R. (2011). Conceptualising citizen's trust in e-government: Application of Q methodology. Leading Issues in E-Government, 1, 204-230.

Ayyash, M. M., Ahmad, K., \& Singh, D. (2013). Investigating the effect of information systems factors on trust in e-government initiative adoption in Palestinian public sector. Research Journal of Applied Sciences, Engineering and Technology, 5(15), 3865-3875.
Baccarella, C. V., Wagner, T. F., Kietzmann, J. H., \& McCarthy, I. P. (2018). Social media? It's serious! Understanding the dark side of social media. European Management Journal, 36(4), 431-438.

Bélanger, F., \& Carter, L. (2008). Trust and risk in egovernment adoption. The Journal of Strategic Information Systems, 17(2), 165-176.

Bhimani, H., Mention, A. L., \& Barlatier, P. J. (2018). Social media and innovation: A systematic literature review and future research directions. Technological Forecasting and Social Change, in press.

Bonsón, E., Torres, L., Royo, S., \& Flores, F. (2012). Local e-government 2.0: Social media and corporate transparency in municipalities. Government information quarterly, 29(2), 123132.

Chatzoglou, P., Chatzoudes, D., \& Symeonidis, S. (2015, September). Factors affecting the intention to use e-Government services. Federated Conference on Computer Science and Information Systems, 1489-1498.

Cheung, M. F., \& To, W. M. (2017). The influence of the propensity to trust on mobile users' attitudes toward in-app advertisements: An extension of the theory of planned behavior. Computers in Human Behavior, 76, 102-111.

Colesca, S. E. (2009). Understanding trust in egovernment. Engineering Economics, 63(4), 715 .

Criado, J. I., Sandoval-Almazan, R., \& Gil-Garcia, J. R. (2013). Government innovation through social media. Government Information Quarterly, 30(4), 319-326.

Davis, F. D., Bagozzi, R. P., \& Warshaw, P. R. (1989). User acceptance of computer technology: a comparison of two theoretical models. Management science, 35(8), 982-1003.

Dhillon, G., Oliveira, T., \& Syed, R. (2018). Value-based Information Privacy Objectives for Internet Commerce. Computers in Human Behavior, 87, 292-307.

Dong, T., Liang, C., \& He, X. (2017). Social media and internet public events. Telematics and Informatics, 34(3), 726-739.

Featherman, M. S., \& Pavlou, P. A. (2003). Predicting eservices adoption: a perceived risk facets perspective. International journal of humancomputer studies, 59(4), 451-474.

Fishbein, M., \& Ajzen, I. (1975). Belief, attitude, intention and behavior: An introduction to theory and research. Reading, MA: Addison-Wesley. 
Gajendra, S., Xi, B., \& Wang, Q. (2012). E-government: Public participation and ethical issues. Journal of e-Governance, 35(4), 195-204.

Guillamón, M. D., Ríos, A. M., Gesuele, B., \& Metallo, C. (2016). Factors influencing social media use in local governments: The case of Italy and Spain. Government Information Quarterly, 33(3), 460-471.

Gupta, K. P., Singh, S., \& Bhaskar, P. (2016). Citizen adoption of e-government: a literature review and conceptual framework. Electronic Government, an International Journal, 12(2), 160-185.

Ho, K. T., \& Li, C. (2011). From Privacy Concern To Uses Of Social Network Sites: A Cultural Comparison Via User Survey. Proceedings 2011 IEEE International Conference On Privacy, Security, Risk And Trust And IEEE International Conference On Social Computing, 457-464.

Hong, H. (2013). Government websites and social media's influence on government-public relationships. Public Relations Review, 39(4), 346-356.

Horst, M., Kuttschreuter, M., \& Gutteling, J. M. (2007). Perceived usefulness, personal experiences, risk perception and trust as determinants of adoption of e-government services in The Netherlands. Computers in Human Behavior, 23(4), 18381852.

Hung, S. Y., Chang, C. M., \& Yu, T. J. (2006). Determinants of user acceptance of the eGovernment services: The case of online tax filing and payment system. Government Information Quarterly, 23(1), 97-122.

Kaplan, A. M., \& Haenlein, M. (2010). Users of the world, unite! The challenges and opportunities of Social Media. Business horizons, 53(1), 59-68.

Kassen, M. (2014). Globalization of e-government: open government as a global agenda; benefits, limitations and ways forward. Information Development, 30(1), 51-58.

Kietzmann, J. H., Hermkens, K., McCarthy, I. P., \& Silvestre, B. S. (2011). Social media? Get serious! Understanding the functional building blocks of social media. Business horizons, 54(3), 241-251.

Liu, Y., \& Zhou, C. (2010). A citizen trust model for egovernment. IEEE International Conference on Software Engineering and Service Sciences, 751-754.

Martin, K. (2018). The penalty for privacy violations: How privacy violations impact trust online. Journal of Business Research, 82, 103-116.
Mayer, R. C., Davis, J. H., \& Schoorman, F. D. (1995). An integrative model of organizational trust. Academy of management review, 20(3), 709734.

McKnight, D. H., Cummings, L. L., \& Chervany, N. L. (1998). Initial trust formation in new organizational relationships. Academy of Management review, 23(3), 473-490.

McKnight, D. H., Kacmar, C. J., \& Choudhury, V. (2004). Dispositional trust and distrust distinctions in predicting high-and low-risk internet expert advice site perceptions. E-Service, 3(2), 35-58.

Moon, M. J. (2002). The evolution of e-government among municipalities: rhetoric or reality?. Public administration review, 62(4), 424-433.

Nunnally, J. C. (1978). Psychometric Theory (2nd ed.), New York, McGraw-Hill.

Obar, J. A., \& Wildman, S. S. (2015). Social media definition and the governance challenge-an introduction to the special issue. Telecommunications Policy, 39, 745-750.

Osimo, D. (2008). Web 2.0 in government: Why and how. Institute for Prospectice Technological Studies (IPTS), JRC, European Commission, EUR, 23358.

Parent, M., Vandebeek, C. A., \& Gemino, A. C. (2005). Building citizen trust through e-government. Government Information Quarterly, 22(4), 720736 .

Park, M. J., Choi, H., Kim, S. K., \& Rho, J. J. (2015). Trust in government's social media service and citizen's patronage behavior. Telematics and Informatics, 32(4), 629-641.

Porumbescu, G. A. (2016). Linking public sector social media and e-government website use to trust in government. Government Information Quarterly, 33(2), 291-304.

Ranaweera, H. M. B. P. (2016). Perspective of trust towards e-government initiatives in Sri Lanka. SpringerPlus, 5(22), 1-11.

Ratnasingam, P. (2004). The role of facilitating conditions in developing trust for successful electronic marketplace participation. Journal of Internet commerce, 3(3), 95-110.

Sá, F., Rocha, Á., \& Cota, M. P. (2016). Potential dimensions for a local e-Government services quality model. Telematics and Informatics, 33(2), 270-276.

Teo, T. S., Srivastava, S. C., \& Jiang, L. (2008). Trust and electronic government success: An empirical study. Journal of management information systems, 25(3), 99-132. 
Tolbert, C. J., \& Mossberger, K. (2006). The effects of egovernment on trust and confidence in government. Public administration review, 66(3), 354-369.

Van Ryzin, G. G. (2007). Pieces of a puzzle: Linking government performance, citizen satisfaction, and trust. Public Performance \& Management Review, 30(4), 521-535.

Venkatesh, V., Morris, M. G., Davis, G. B., \& Davis, F. D. (2003). User acceptance of information technology: Toward a unified view. MIS quarterly, 27(3), 425-478.

Warkentin, M., Gefen, D., Pavlou, P. A., \& Rose, G. M. (2002). Encouraging citizen adoption of egovernment by building trust. Electronic markets, 12(3), 157-162.

Welch, E. W., Hinnant, C. C., \& Moon, M. J. (2004). Linking citizen satisfaction with e-government and trust in government. Journal of public administration research and theory, 15(3), 371391.

Xu, J. D., Cenfetelli, R. T., \& Aquino, K. (2016). Do different kinds of trust matter? An examination of the three trusting beliefs on satisfaction and purchase behavior in the buyer-seller context. The Journal of Strategic Information Systems, 25(1), 15-31.

Yildiz, M. (2007). E-government research: Reviewing the literature, limitations, and ways forward. Government information quarterly, 24(3), 646665.

Yoon, S. J. (2002). The antecedents and consequences of trust in online-purchase decisions. Journal of interactive marketing, 16(2), 47-63. 